\title{
Clinical examination compared with anthropometry in evaluating nutritional status
}

\author{
J H Cross, C Holden, A MacDonald, G Pearmain, M C G Stevens, I W Booth
}

\begin{abstract}
Clinical assessments of nutritional status in a group of 44 inpatients, made by a panel of experienced childcare specialists, were compared with anthropometric assessments. Assessors were uniformly poor at detecting severe malnutrition and at assessing the nutritional status of infants. Nutritional status cannot be accurately assessed clinically and anthropometry is crucial.
\end{abstract}

(Arch Dis Child 1995; 72: 60-61)

Keywords: anthropometry, clinical assessment, nutritional status.

Assessment of nutritional status is an essential component of the clinical examination of children. Most assessments take place in the busy clinic when formal anthropometry is not easily performed. Instead reliance is placed upon an overall global assessment of nutritional status by observation and clinical examination. In adults, clinical evaluation alone may be an adequate substitute for anthropometric assessment or biochemical indices of nutritional status. ${ }^{1}$ The assumption that an equivalent situation exists in infancy and childhood has never been formally tested. We have therefore measured the ability of three experienced childcare professionals to grade the nutritional status of patients of varying ages and nutritional status.

\section{Subjects}

Subjects were selected by one member of the study team (JHC). Children were selected from three different age groups. All subjects were in hospital for at least three days to enable complete assessment, and were unknown to the panel of assessors. Forty four patients (25 boys, 19 girls) were entered into the study: 16 under 12 months, 11 patients between 13 months and 5 years, and 17 over 5 years of age.

All three assessors were involved in the day to day management of malnourished children and were selected to provide an experienced, multidisciplinary team from within the Children's Hospital. The panel comprised a

Anthropometric allocation to nutritional group

\begin{tabular}{llcc}
\hline Group & $\begin{array}{l}\text { Clinical } \\
\text { assessment }\end{array}$ & $\begin{array}{l}\text { MUAC }{ }^{2}: \\
\text { (centile) }\end{array}$ & $\begin{array}{l}\text { MUAC } \\
<12 \text { months } \\
\text { (\% of standard) }\end{array}$ \\
\hline A & Severe malnutrition & $<5$ th & $<75$ \\
B & Mild malnutrition & 5th-25th & $75-90$ \\
C & Normal & 25th-75th & $90-110$ \\
D & Over nutrition & $>75$ th & $>110$
\end{tabular}

consultant paediatric oncologist, a senior dietitian, and a senior clinical nurse specialist.

\section{Methods}

ANTHROPOMETRIC ASSESSMENT

Measurements of mid upper arm circumference (MUAC) were made by one of two examiners. Each child was allocated to one of four arbitrarily defined anthropometric groups indicated in the table. Nine children were severely malnourished (group A); 15 were mildly malnourished (group B); 15 were normal (group C), and six were obese (group D).

\section{CLINICAL ASSESSMENT}

The panel of assessors examined each subject, and were asked to allocate each child to one of the four clinical groups based upon their assessment of wasting or obesity. They were allowed to touch the subjects. They were not asked to comment on stunting. Each assessor was blind to the results of anthropometry and to their colleagues' assessments. Clinical observations were compared directly with anthropometric grouping.

\section{Results}

One hundred and thirty two observations were made by three assessors on the 44 patients. Eighty five observations were in agreement with the MUAC grouping, giving a concordance of $64 \%$. In $18(41 \%)$ patients there was complete agreement among all three assessors but not necessarily with the MUAC; in 14 $(32 \%)$ patients there was unanimous agreement between all assessors and the MUAC grouping.

Figure 1 shows concordance data classed according to each nutritional group and shows that assessors were uniformly poor at identifying severe malnutrition. The difference in concordance between group $\mathrm{A}$ and all three other groups was significant $(p<0.05)$. The accuracy of clinical assessment improved with improving nutritional status.

Figure 2 shows concordance between examiners and MUAC according to age grouping. Examiners were significantly poorer at classifying infants when compared with either of the other two age groupings $(p<0 \cdot 01)$.

\section{Discussion}

This study has shown that anthropometric evaluation is necessary in children for the accurate assessment of nutritional status.
Dr J H Cross, The Wolfso Centre, Mecklenburgh Square, Londo

Accepted 4 October 1994 


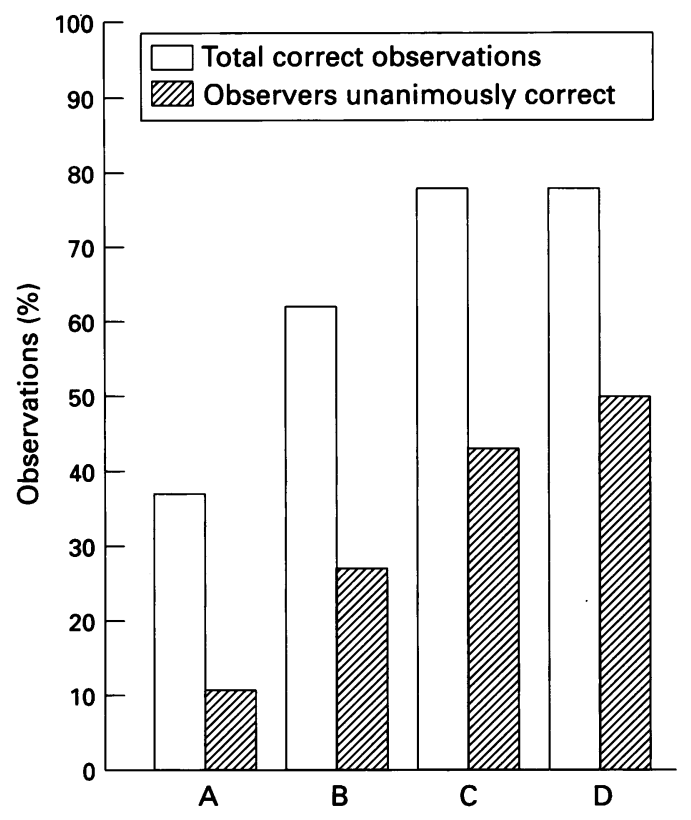

Nutritional status grouping by MUAC

Figure 1 Histogram showing the number of correct observations of nutritional status by clinical assessors compared with MUAC grouping. The difference in concordance between group $A$ and all three other groups was significant $(p<0 \cdot 05)$.

MUAC was used as opposed to other forms of anthropometric measurement in view of ease of measurement and the high degree of reproducibility. It is also a measurement unaffected by body water, is the least age dependent, and has been shown to be the best predictor of death secondary to malnutrition. ${ }^{4}$

The assessors were uniformly poor at recognising the severely malnourished. This may have been affected by the population of patients used, as the length of time required for full evaluation may have selected out the more severely ill. It may also be that the findings reflect the population of children regularly reviewed in normal practice by the examiners so that the concept of 'normal' is adjusted. The study has also shown the poor ability of the assessors to judge the nutritional status of infants. Accuracy improved with increasing age group.

Of note is that all the panel of assessors were experienced professionals in child care. The majority of routine clinical assessments are performed by more junior and less experienced

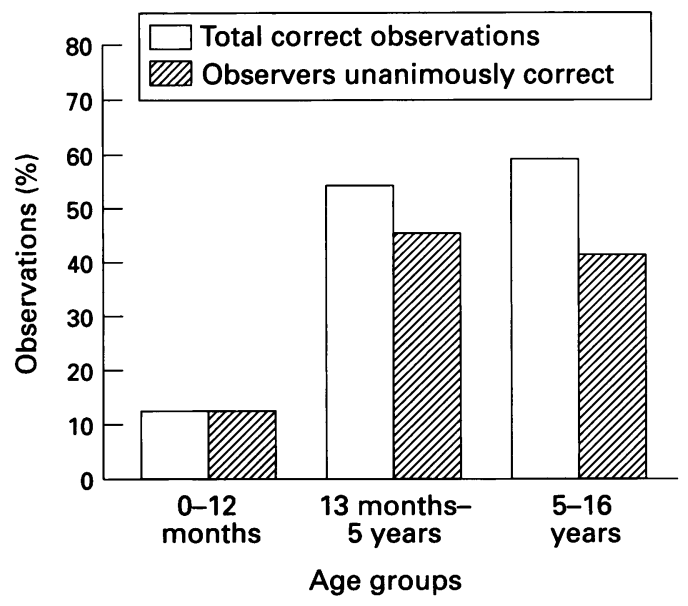

Figure 2 Histogram showing the number of correct observations of nutritional status by clinical assessors classed according to age group. Examiners were significantly poorer at classifying infants when compared with either of the other two age groupings $(p<0 \cdot 01)$

staff in the outpatient or casualty departments. Unfortunately, we were unable to include a junior doctor on the panel of assessors in view of inconsistent availability, but it is of concern that reproducibility in clinical assessment of nutritional status is poor, even among senior staff, especially in the more severely malnourished. It seems plausible that more junior staff would be even less reliable.

In conclusion, we have found that clinical evaluation of nutritional status alone is inadequate for accurate assessment and follow up, and that anthropometry is essential. We suspect that our institution is not alone in frequently falling short of this ideal, despite the recognition that malnutrition is common among children in hospital. ${ }^{5}$

1 Baker JP, Detsky AS, Wessen DE, et al. Nutritional assessment: a comparison of clinical judgement and objective measurement. $N$ Engl F Med 1982; 306: 969-72.

2 Frisancho AR. New norms of upper limb fat and muscle areas for assessment of nutritional status. $\mathrm{Am} \mathcal{F}$ Clin Nutr 1981; 34: 2540-5.

3 Burgess HJL, Burgess AP. The arm circumference as a public health index of protein-calorie malnutrition of early childhood. (II) A modified standard for mid-upper arm circumference in young children. $\mathcal{\exists}$ Trop Pediatr $1969 ; 15$ : 189-92.

4 Briend A, Dykewicz C, Graven K, Mazumder RN, Wojtyniak B, Bennish M. Usefulness of nutritional indices Wojtyniak B, Bennish M. Usefulness of nutritional indices
and classifications in predicting death of malnourished and classifications in predicting

5 Moy RJD, Smallman S, Booth IW. Malnutrition in a UK children's hospital. Fournal of Human Nutrition and Dietetics 1990; 3: 93-100. 